\title{
La inserción socioprofesional de los inmigrantes en Andalucía
}

\author{
Rafael Martínez Martín \\ Juan Carlos Prior Ruiz \\ Universidad de Granada. Departamento de Sociología \\ rmmartin@ugr.es; jprior@ugr.es
}

Recibido: 16-04-2010

Aceptado: 30-05-2011

\begin{abstract}
Resumen
En las últimas décadas, un fenómeno nuevo ha irrumpido de forma intensa, rápida y estable en las sociedades española y andaluza. Nos referimos a la inmigración económica. Las políticas sobre inmigración han mostrado un interés permanente en conseguir la integración social de los extranjeros en los países de acogida. La importancia del empleo no ha pasado desapercibida para las políticas de integración social ni para los propios inmigrantes económicos, ya que constituye la principal fuente de renta y de estatus de los individuos en nuestra sociedad. Partimos de la hipótesis, más verificada que rechazada, de que la integración social está íntimamente relacionada con la inserción en el mercado de trabajo y el desarrollo de unas trayectorias laborales estables. Por ello, en el presente artículo, nos centramos en analizar la inserción socioprofesional de los inmigrantes económicos en la comunidad autónoma de Andalucía como indicador fundamental a la hora de estimar sus posibilidades de integración social.
\end{abstract}

Palabras clave: inmigración; mercado de trabajo; inserción profesional; integración social.

\section{Abstract. The socio-professional insertion of immigrants in Andalusia}

In the last few decades a new phenomenon has burst intensively and rapidly into Spanish and Andalusian societies, and established itself: economic immigration. Immigration policies have shown a continuous interest in achieving the social integration of foreigners in host societies. The importance of employment has not gone unnoticed by social integration policies, nor by the economic immigrants themselves, since employment is the main source of income and status for individuals in our society. We begin from the hypothesis, more accepted than rejected, that achieving social integration is closely related to entering the labour market and maintaining stable employment. For this reason the present article focuses on analysing the socio-professional inclusion of economic immigrants in the autonomous community of Andalusia, as a fundamental indicator of their possibilities of social integration.

Key words: immigration; labour market; professional insertion; social integration. 


\section{Sumario}

\section{Introducción}

2. Planteamiento de la investigación

3. Las políticas de inmigración y la integración social

4. Los inmigrantes en Andalucía y su situación laboral
5. Itinierarios laborales: el proceso de inserción socioprofesional

6. Conclusiones

7. Bibliografía

\section{Introducción}

La década de 1990 trajo consigo una nueva realidad para la sociedad andaluza. Nos referimos al cambio de signo de las migraciones. El fenómeno de la inmigración por motivos económicos adquiere rapidez e intensidad. La comunidad andaluza pierde su condición de región exportadora de mano de obra a otros contextos españoles y europeos, para convertirse en receptora de inmigrantes, procedentes, en su mayoría, de países no comunitarios. El objetivo económico se convierte en la principal motivación de los inmigrantes, ya que el hecho de poder conseguir un trabajo y el acceso a los servicios característicos de una sociedad de bienestar marcan el denominado saldo vital que explica su significativa relevancia.

El fenómeno de la inmigración irrumpe en el contexto de Andalucía de forma paralela a su desarrollo económico. El auge del turismo y la expansión, sin precedentes, del sector de la construcción generan importantes demandas de empleo.

Las significativas desigualdades que caracterizan al contexto mundial están marcando el signo de las migraciones. Lo más habitual es que provengan de zonas caracterizadas por la desestructuración, el conflicto y las desigualdades sociales. En las sociedades de acogida, los recién llegados son percibidos como los otros; con un estatus, una apariencia física, una religión y otras características que inciden en la relación entre inmigrantes y sociedad receptora para determinar la dirección y los resultados del proceso de integración (Tezanos, 2006).

La inmigración ha traído consigo el multiculturalismo, nuevos conflictos sociales y nuevas formas de consenso. Nos enfrentamos a un novedoso panorama social marcado por el pluralismo cultural que es necesario gestionar. En este contexto, marcado por la interacción de dos sociedades diferentes, la integración se convierte en un objetivo prioritario para la sociedad. Las políticas y las líneas de investigación social lo han puesto de manifiesto, al constituir las migraciones una temática central.

La integración supone la presencia y la incorporación de los inmigrantes en una sociedad con una estructura social y una cultura consolidadas, donde se diferencian cuatro dimensiones: ocupacional, urbana, política y sociocultural (Solé, 1988). En la misma línea, Penninx y Martiniello (2006) lo entienden 
como un proceso a través del cual uno se convierte en una parte aceptada de la sociedad, y Urteaga (2010: 38) la define como «un proceso que consiste en pasar de la alteridad más radical a la identidad más total». En general, la integración es concebida como un equilibrio de derechos y obligaciones. Se incluyen como objetivos todas las dimensiones de la integración: derechos sociales, económicos y políticos; la diversidad cultural y religiosa, la ciudadanía y la participación.

Los mecanismos de integración social son los que permiten alcanzar una sociedad más cohesionada y por ello se dirigen hacia distintos ámbitos, en los cuales destaca la importancia de la integración laboral. El empleo, como principal fuente de renta y estatus de los individuos, constituye un factor fundamental para la integración de los inmigrantes económicos en las sociedades receptoras.

En el presente artículo, se analiza el reciente fenómeno de la inmigración en Andalucía en relación con el mercado de trabajo. Pretendemos conocer el acceso de los inmigrantes al mercado laboral, así como sus formas de acceso a él. Los itinerarios laborales que describen resultan de especial interés a la hora de conocer y valorar la inserción laboral de los colectivos de inmigrantes. Partimos de la hipótesis, más verificada que rechazada, de que la integración de los inmigrantes económicos en el mercado de trabajo constituye un factor determinante para su integración social.

\section{Planteamiento de la investigación}

El interés científico y académico por conocer y analizar los procesos de inserción socioprofesional que experimentan los individuos deviene de la crisis energética de la década de 1970. La subida del precio del petróleo, los procesos de globalización económica, la incorporación de nuevas tecnologías de la información en las empresas y las políticas de flexibilización laboral incidieron de forma decisiva en la configuración de un nuevo mercado de trabajo. En este contexto, el desempleo afectó de forma generalizada a los países industrializados, para convertirse en un elemento estructural de las economías desarrolladas.

Las transformaciones del mercado de trabajo en Andalucía, manifiestas desde la década de 1980, han marcado un nuevo panorama laboral caracterizado por la imprevisibilidad, en cuanto a la incorporación al empleo de las nuevas generaciones y en lo relativo a los itinerarios laborales que describen los individuos. Mientras el mercado de trabajo tradicional era previsible y respondía a unas expectativas asentadas en la sociedad, la nueva realidad emergente se caracteriza por la incertidumbre asociada a su creciente flexibilización.

El estudio y el análisis del acceso al empleo, así como de los itinerarios laborales que describen los individuos, adquiere un protagonismo especial ante los excesivos niveles de desempleo y de precariedad laboral que caracterizan al mercado de trabajo andaluz. Estos cambios, de carácter estructural y legislativo, han traído consigo importantes retrasos a la hora de acceder a la vida activa y al empleo. En concordancia con la flexibilización que experimenta el 
mercado de trabajo, los individuos desarrollan trayectorias laborales marcadas por la diversidad de situaciones y la incertidumbre. En muchas ocasiones, la integración social del sujeto queda relegada a su situación en el mercado de trabajo (Martínez, 2002).

En este escenario laboral, el concepto de inserción socioprofesional ha dejado de concebirse como un proceso homogéneo, que abarcaría el periodo comprendido entre la salida del sistema escolar hasta la obtención del primer empleo, para ser entendido como un proceso mucho más complejo que comprende todo un conjunto de líneas de carrera, itinerarios laborales, trayectorias de trabajo o modelos de transición a la vida activa, todos ellos condicionados por hechos psicosociales. Estos procesos laborales son definidos como «una secuencia de experiencias de trabajo de una persona a lo largo del tiempo» (Poole y otros, 1993: 40). Cada secuencia de actividades suele conllevar una transición nueva dentro del mercado laboral que supone nuevos roles y, por tanto, reorientación de metas, actitudes, identidades, redes informales y otros muchos cambios (Ashforth y Saks, 1995). En buena medida, los estudios sobre integración social se han desarrollado de forma paralela a esta realidad, con el objetivo de mejorar el tránsito a la vida activa y al trabajo. El acceso al empleo y la integración social constituyen procesos íntimamente relacionados entre sí (Figuera, 1996; Auberni, 1995; Casal, Masjoan y Planas, 1991; Coleman y Husén, 1989; Ashforth y Saks, 1995).

Desde la sociología, se estudia de forma profusa la nueva realidad laboral en relación con los procesos de inserción social. El individuo, a lo largo de su vida, pasa por varias etapas de transición: de la escuela a la escuela, de la escuela al trabajo, del trabajo a otro trabajo, de la familia a la familia y del trabajo a la jubilación. El concepto de transición ha sido entendido de forma ambivalente: como transición a la vida activa y como transición a la vida adulta. La inserción socioprofesional hace referencia al momento en que culmina el proceso de transición en sus dos dimensiones: dimensión social (transición a la vida adulta) y dimensión laboral (transición a la vida activa), producto de la articulación compleja de formación, inserción profesional y emancipación familiar. Son términos que hacen referencia a la idea de que la transición es un proceso sociohistórico (determinado socialmente y diferenciado en el espacio y en el tiempo), configurado por una diversidad interna de itinerarios (distintas situaciones de salida, distintos tránsitos y distintas situaciones de llegada), de carácter biográfico (atañe al desarrollo social del individuo en vista a tomar carta de adulto) y estructurado (determinado a nivel institucional y político) (Casal, Masjoan y Planas, 1991: 9 y s.).

La correlación positiva entre el mayor grado de integración social y acceso al mercado laboral encuentra más argumentos para verificarse que para rechazarse. El acceso al mercado laboral es concebido como el primer paso en la aceptación progresiva de instituciones, creencias, valores y símbolos de la sociedad receptora (Solé y otros, 2002).

Si el trabajo constituye un medio muy relevante para la integración en la sociedad, resulta de especial importancia conocer y analizar el mercado laboral 
de los inmigrantes. El acceso al empleo y las formas de acceso que se describen, determinan importantes facetas de la vida de las personas; en buena medida, trazan y definen las etapas vitales y, de forma cada vez más evidente, la integración en la sociedad. La importancia del empleo no pasa desapercibida para la sociedad en general, y especialmente para los inmigrantes.

La estrategia metodológica aplicada ha consistido en la revisión bibliográfica, documental y de fuentes de datos oficiales. Con esta metodología, se ha conseguido alcanzar, con mayor rigor, el objetivo de conocer y analizar el mercado laboral de los inmigrantes en Andalucía. Los inmigrantes económicos son los que requieren mayor atención, por parte de la sociedad y de la Administración pública, y su integración social está claramente impregnada por su situación en el mercado de trabajo.

Entre las principales fuentes oficiales que hemos utilizado, caben destacar: la Encuesta nacional de inmigrantes (ENI), gestionada por el Instituto Nacional de Estadística en el año 2007, que permite la realización de distintos análisis de carácter socioeconómico y nos posibilita la obtención de información valiosa a la hora de conocer las trayectorias laborales de los inmigrantes en Andalucía; el Observatorio Permanente Andaluz de las Migraciones (OPAM), dependiente de la Consejería de Empleo de la Junta de Andalucía, incluye una amplia oferta informativa y de bases estadísticas para acceder y analizar importantes facetas laborales del hecho migratorio en Andalucía; el Padrón municipal continuo de habitantes, coordinado por el Instituto Nacional de Estadística, es una fuente de especial interés para el estudio del volumen y de las características de la inmigración en Andalucía, ya que, desde el año $2000^{1}$, el hecho de empadronarse conlleva importantes incentivos sociales, como el acceso al sistema educativo y sanitario, que ha impulsado la inscripción; la Encuesta de población activa (EPA), realizada por el Instituto Nacional de Estadística (INE), es la fuente oficial para conocer las magnitudes del mercado de trabajo en España y ofrece información acerca de los activos, ocupados y desempleados en función de la nacionalidad, y el observatorio ARGOS (Sistema de Prospección Permanente del Mercado de Trabajo), perteneciente a la Consejería de Empleo de la Junta de Andalucía, proporciona información constante sobre el mercado laboral de los extranjeros y ha sido una fuente de gran utilidad para conocer los indicadores más recientes sobre contratos y demandas de empleo.

A continuación, se hace referencia a las principales acciones en materia de inmigración desarrolladas por la Administración andaluza, todas ellas centradas en la integración social de los inmigrantes.

\section{Las políticas de inmigración y la integración social}

Las políticas sobre inmigración muestran de forma asidua términos como cohesión social, integración social, asimilación, adaptación e inserción. La complejidad

1. Ley Orgánica 4/2000, de 11 de enero, sobre derechos y libertades de los extranjeros en España y su integración social. 
de los términos ha puesto de manifiesto su uso dispar. En la literatura francesa son habituales términos como adaptación e inserción social, frente a los de asimilación, integración y aculturación, que presentan determinadas connotaciones referentes a la pérdida de identidad cultural de los inmigrantes (Herrera, 1994).

En el contexto de la Unión Europea (UE), las políticas sobre inmigración han ido experimentando una evolución que se plasma en tres periodos. En el primero, comprendido entre los años 1960 y 1970, la integración de los inmigrantes consiste en obtener el estatus de ciudadanos. Para ello, es fundamental acceder al empleo y a la participación política, lo cual propicia la asimilación de valores y normas del país de acogida. En un segundo periodo, comprendido entre los años 1980 y 1990, los modelos de integración se definen en función de la concepción del trabajo inmigrante, del código de la nacionalidad y de la relación con las minorías étnicas. El tercer periodo de integración, el más actual, se basa en el endurecimiento de las condiciones de acceso de los inmigrantes al permiso de residencia y de trabajo, así como a la nacionalidad. Se intensifica la lucha contra la inmigración ilegal y aumentan los controles en las fronteras. En este contexto, los países desarrollan programas de integración cívica para propiciar su asimilación (Urteaga, 2010).

La Comisión Europea plantea retos relativos a la integración de los inmigrantes como instrumento para alcanzar la mayor cohesión social en las nuevas sociedades pluriculturales. La cohesión social designa el nivel de consenso de los miembros de un grupo social en la pertenencia a un proyecto común. La solidaridad y la cohesión social son parte del orden moral indispensable para que los individuos continúen vinculados a la sociedad. Es fundamental incrementarla, ya que posibilita mayores apoyos a las políticas públicas destinadas a educación, sanidad y redistribución de ingresos; también aumenta la aceptabilidad de las normas de conducta y de valores compartidos, de las instituciones sociales y la confianza a las leyes y a la justicia; sin olvidar el impulso a la participación en la sociedad civil y el refuerzo del capital social (Solé y otros, 2011).

La noción de integración es entendida como un proceso de reducción de las disparidades sociales y construcción de valores y acuerdos comunes. En la investigación llevada a cabo por Pennix y Martiniello (2006), se constata que, para conseguir la integración de los inmigrantes en las sociedades de acogida, es necesario dar respuesta a todo un conjunto de necesidades que presentan, tales como: vivienda, trabajo, educación, salud y otros aspectos culturales, como son sus obligaciones religiosas y el uso y la enseñanza de sus idiomas maternos.

En el contexto de Andalucía, aunque el Estado ostenta las competencias en materia de nacionalidad, inmigración, emigración, extranjería y derecho de asilo; la Junta de Andalucía tiene atribuidas competencias para la prestación de servicios básicos relativos a sanidad, educación, vivienda, políticas activas de empleo, atención al menor e igualdad, entre otros servicios sociales. Son muchas y variadas las actuaciones que se desarrollan desde consejerías, organismos autónomos, ayuntamientos y otras instituciones, con el propósito de dar respuesta a las variadas y complejas necesidades de los inmigrantes. 
En la década de 1980, cuando la inmigración empezaba a ser una realidad tímidamente visible, las ONG asumieron un papel activo en la atención a las necesidades de los inmigrantes, al mismo tiempo que reclamaban una mayor atención de la Administración bajo consignas religiosas y humanitarias. Como afirman Solé y otros (2000), antes del año 1985, existía en España una indiferencia institucional y social hacia los inmigrantes. La figura del inmigrante no se había construido y la imagen del extranjero tenía unas connotaciones positivas, al relacionarlo con la población de países ricos europeos. Con la aprobación de la Ley de extranjería ${ }^{2}$, se crearon categorías jurídicas (inmigrante ilegal, irregular, extracomunitario, etc.) que pronto se convirtieron en categorías simbólicas, y el inmigrante económico se convierte en el pobre de los países del Tercer Mundo.

En los primeros años de la década de 1990, se libran las primeras ayudas económicas destinadas a la integración de los inmigrantes. La Consejería de Trabajo y Asuntos Sociales de la Junta de Andalucía comienza a intervenir en el desarrollo de programas de prevención y promoción social, entre ellos el fomento del asociacionismo inmigrante. En 1992, se crea el Servicio de Inmigración de la Junta de Andalucía, cuyo cometido es el diseño de las actuaciones de la Consejería en materia de migraciones; y, en 1995, se pone en marcha el Proyecto para la Inserción Social y Laboral de los Inmigrantes Extranjeros en Andalucía, encuadrado dentro de la Iniciativa Comunitaria HORIZÓN. Gracias a este proyecto, se crearon once centros de orientación, gestionados por corporaciones locales, sindicatos y la federación Andalucía Acoge, así como todo un conjunto de acciones complementarias de formación. De forma paralela, comienzan a desarrollarse programas específicos para inmigrantes en la red básica de Servicios Sociales Comunitarios, y las universidades andaluzas inician investigaciones sobre este reciente fenómeno socioeconómico (Pumares e Iborra, 2008).

Ante la necesidad de seguir impulsando medidas de integración social, dentro de la iniciativa INTEGRA financiada por el Fondo Social Europeo, se pone en marcha el Proyecto Diversidad para la integración de colectivos en riesgo de exclusión social. A partir de este proyecto, se crearon cinco centros para la orientación y el fomento del empleo de los inmigrantes en Andalucía, y se pone en marcha el Observatorio Permanente Andaluz de las Migraciones

2. En el año 1985, se promulga la Ley de extranjería (Ley Orgánica 7/1985, sobre derechos y libertades de los extranjeros en España) para potenciar la visión de los inmigrantes como fuerza de trabajo, ya que el permiso de trabajo, el contrato laboral y el permiso de residencia son mutuamente dependientes. La Ley Orgánica 4/2000, sobre derechos y libertades de los extranjeros en España y su integración social, supone avances respecto a la ley anterior, al reconocer derechos básicos a los extranjeros: educación, sanidad, ayudas a la vivienda, asociación, justicia gratuita y sindicación. No obstante, la nueva ley sigue manteniendo el permiso de trabajo como exigencia previa para acceder al mercado laboral y no se elimina la referencia a la situación nacional del empleo. Es decir, la concesión y renovación de los permisos de trabajo está sujeta a la existencia de españoles en paro en las actividades propuestas y en la insuficiencia y escasez de mano de obra autóctona en la actividad y en la zona geográfica donde se pretende trabajar (Solé y otros, 2000). 
(OPAM) para el diagnóstico y el análisis de la realidad inmigratoria. Aunque los avances han sido considerables durante la década de 1990, quedan importantes escollos por superar, sobre todo en materia de educación y vivienda. A lo largo de los años 2001 y 2005, desde el gobierno regional andaluz, se activa el I Plan Integral para la Inmigración en Andalucía. Este plan contaría con la participación de todos los agentes y actores vinculados a la inmigración, con el objetivo de favorecer la plena integración social, laboral y personal de la población inmigrante. Para ello, se definen diez áreas de intervención, entre ellas la sociolaboral.

Siguiendo las aportaciones de Pumares e Iborra (2008), la idoneidad de establecer mecanismos de coordinación entre las administraciones generales, autonómicas y locales responde a una realidad a la que hay que dar repuestas eficientes e integrales. Con el desarrollo del II Plan Integral para la Inmigración en Andalucía (2006-2009), se crea un mecanismo de coordinación interadministrativa que potencia las actuaciones a nivel local. Además, se cuadruplican los recursos económicos, con respecto al I Plan, y se pone en marcha el Fondo de Apoyo a la Acogida e Integración de Inmigrantes. Se refuerza claramente el área educativa y Andalucía asume la atención integral sociosanitaria de los extranjeros, aunque no estén empadronados. Desde el Área de Bienestar Social, se impulsa el asociacionismo, se facilita el acceso a los servicios sociales normalizados y se incluyen programas de atención a menores no acompañados y a mujeres víctimas de violencia de género. Otras áreas como equipamiento y vivienda, investigación, formación y sensibilización social también experimentan mejoras considerables.

En la actualidad, está en marcha el III Plan Integral para la Inmigración en Andalucía 2009-2012. Este nuevo proyecto prevé, hasta 2013, una inversión de 2.500 millones de euros (1.300 más que el anterior plan) e incide especialmente en educación, salud y una mayor intervención del Servicio Andaluz de Empleo (SAE), con el objetivo de favorecer los flujos migratorios y las contrataciones en origen. En lo que respecta al área sociolaboral, se refuerza su descentralización de forma notoria. La aprobación de la nueva normativa (Ley de empleo 56/2003, de 16 de diciembre) establece, entre otras muchas medidas, el marco competencial de las políticas de empleo. En concreto, las políticas activas de empleo pasan a ser competencia de las comunidades autónomas. En el caso de Andalucía, se crea el Servicio Andaluz de Empleo (SAE), encargado de llevarlas a cabo. Se desarrollan acciones de orientación y formación en los sectores que mayor potencialidad de empleo presentan para los inmigrantes extranjeros, tales como: agricultura, construcción, servicio doméstico y hostelería.

La integración pasa por reconocer a los inmigrantes como personas, aunque se ha resaltado la importancia de los factores laborales y de redistribución de recursos. Por ello, las políticas de inmigración deben ir más allá de conseguir la inserción en el mercado de trabajo y de la prestación de servicios sanitarios y educativos, para avanzar hacia un modelo integral que permita reconocer las culturas, las lenguas y las costumbres de los inmigrantes. 
La ciudadanía se ha considerado como el paso hacia la plena integración de los extranjeros en una sociedad. La integración no sólo ha de ser percibida desde el punto de vista de la adopción, por parte de los inmigrantes, de la cultura de la sociedad de acogida, sino también desde las normas y la cultura de los inmigrantes, siempre que se respeten los principios básicos democráticos comunes (Solé y Cachón, 2006).

A continuación, analizamos las principales características sociodemográficas de los inmigrantes en Andalucía, así como la evolución de su situación laboral en el último quinquenio.

\section{Los inmigrantes en Andalucía y su situación laboral}

En la década de 1990, el flujo migratorio hacia Andalucía ha sido una realidad manifiesta, pero no ha sido hasta el año 2000 cuando se ha apreciado mayor afluencia de inmigración, marcada, en buena medida, por el inicio del ciclo de expansión económica.

Como se puede apreciar en la tabla 1, el número de extranjeros empadronados ha pasado de los 89.641, en el año 1996, a los 704.056, en el año 2010. Se han multiplicado prácticamente por ocho y su mayor crecimiento lo han experimentado a partir del año 2000. Por sexos, en general, se aprecia una mayor presencia de varones que de mujeres, una tendencia que se ha ido atenuando en el último quinquenio. La mayor demanda de empleos en el sector servicios y la creciente pérdida de puestos de trabajo en sectores tradicionalmente ocupados en su mayoría por varones, lo explica.

Los datos del OPAM (2008) ponen de manifiesto que, tanto en la agricultura como en la industria, se han producido pérdidas de empleo, pero éstas han sido menos relevantes que las acontecidas en el sector de la construcción. El sector servicios, el menos afectado por la crisis económica, muestra los mejores indicadores de recuperación y es el único sector donde los inmigrantes extranjeros han visto crecer sus posibilidades de trabajar en puestos vinculados al comercio y hostelería. En función del lugar de nacimiento, los extranjeros europeos son los más representados en todos los años analizados, excepto para el 2005, un año marcado por la significativa expansión económica que ha traído consigo una mayor diversificación de la inmigración con la significativa entrada de extranjeros procedentes de otras nacionalidades, sobre todo latinoamericanos, africanos y de Europa del Este, que han ido ganando terreno a los comunitarios.

La significativa presencia europea no resulta llamativa, ya que Andalucía es un destino que ofrece una elevada calidad de vida y es un lugar de residencia de muchos extranjeros provenientes de Europa, sobre todo de países como Reino Unido, Italia, Francia y Alemania. Pero la primacía de la presencia europea se ha visto también reforzada con los procesos de ampliación de la Unión Europea, que han atraído inmigración económica, la cual ha aumentado con la integración de nuevos miembros en el año 2004, de quince a veinticinco países, y en el año 2007, con la incorporación de Bulgaria y Rumanía, zonas 
Tabla 1. Población extranjera empadronada en Andalucía, por sexo y lugar de procedencia. En cifras absolutas y porcentajes

\begin{tabular}{lcrrc}
\hline Andalucía/años & 1996 & 2000 & 2005 & 2010 \\
\hline Por sexo (en cifras absolutas) & & & & \\
Varones & 45.797 & 67.136 & 227.230 & 368.056 \\
Mujeres & 43.844 & 61.781 & 192.977 & 336.000 \\
Total & 89.641 & $\mathbf{1 2 8 . 9 1 7}$ & $\mathbf{4 2 0 . 2 0 7}$ & $\mathbf{7 0 4 . 0 5 6}$ \\
Lugar de nacimiento (en \%) & & & & \\
Europa & 64,5 & 60,3 & 46,5 & 55,5 \\
Asia & 5,3 & 5 & 3,4 & 3,2 \\
África & 19,6 & 22,9 & 22,4 & 19,5 \\
América & 10,3 & 11,5 & 27,4 & 21,6 \\
Oceanía & 0,3 & 0,3 & 0,3 & 0,2 \\
Total & $\mathbf{1 0 0}$ & $\mathbf{1 0 0}$ & $\mathbf{1 0 0}$ & $\mathbf{1 0 0}$ \\
\hline
\end{tabular}

Fuente: Padrón municipal continuo de habitantes. Instituto Nacional de Estadística (INE) y elaboración propia.

que muestran elevados niveles de emigración hacia Andalucía. En concreto, en las provincias de Córdoba, Granada, Huelva y Sevilla, la nacionalidad más representada es la rumana (ARGOS, 2010).

Por año de llegada a Andalucía, los inmigrantes procedentes de países desarrollados y de África han mostrado un flujo homogéneo desde antes de 1992; mientras los procedentes de América Latina y de otros países europeos, asiáticos y de Oceanía, han llegado, sobre todo, desde el año 1992 y con mayor frecuencia en la última década. Por edades, los de 60 o más años suelen venir de países desarrollados, ya que los inmigrantes económicos suelen proceder de contextos menos desarrollados en busca de nuevas oportunidades laborales. De hecho, la práctica totalidad con edades comprendidas entre los 16 y 59 años —edades activas- han nacido en América Latina y África. No obstante, los que tienen entre 30 y 44 años son los más propensos a emigrar en cualquiera de los contextos analizados. En función de los niveles educativos, cabe destacar que la mayoría, de forma independiente a su lugar de nacimiento, posee estudios medios y superiores. Por tanto, existe un elevado nivel académico característico de los que vienen de países desarrollados, que disminuye en los nacidos en África y América Latina. En concreto, el 89,8\% y el 79,6\% de los africanos y latinoamericanos, respectivamente, tienen estudios secundarios o inferiores, lo cual corrobora los tópicos asociados al menor nivel educativo de los inmigrantes económicos (tabla 2).

\subsection{Situación laboral actual: activos, ocupados y desempleados}

En general, en consonancia con lo ocurrido a nivel nacional, el número de activos en Andalucía ha experimentado un crecimiento en los últimos años. En 2010, el número total de activos ascendía a 3.976.500, de los cuales 2.245.000 eran varones y 1.731 .500 , mujeres. La proporción de activos extranjeros tam- 
Tabla 2. Características sociodemográficas de los inmigrantes según su región de nacimiento. En porcentajes

\begin{tabular}{lcccc}
\hline & $\begin{array}{c}\text { Países } \\
\text { desarrollados }\end{array}$ & $\begin{array}{c}\text { América } \\
\text { latina }\end{array}$ & África & $\begin{array}{c}\text { Otros países de Europa, } \\
\text { Asía y Oceanía }\end{array}$ \\
\hline Año de llegada & & & & \\
Antes de 1992 & 38,7 & 11,3 & 30,8 & 6,9 \\
1992-2001 & 28,3 & 43,6 & 36,4 & 29,6 \\
2002-2007 & 33 & 45,1 & 32,8 & 63,5 \\
Total & 100 & 100 & 100 & 100 \\
Edad & 11 & 34,1 & 32,6 & 36,3 \\
16-29 años & 38,5 & 40,3 & 37,8 & 39,4 \\
30-44 & 18,8 & 20,4 & 20,3 & 22,5 \\
45-59 & 31,7 & 5,2 & 9,3 & 1,8 \\
60 y más & 100 & 100 & $\mathbf{1 0 0}$ & $\mathbf{1 0 0}$ \\
Total & & & & \\
Nivel educativo & 16,6 & 29,2 & 43,3 & 21,2 \\
Primarios o sin estudios & 52,4 & 50,4 & 46,5 & 62,1 \\
Secundaria & 31 & 20,4 & 10,2 & 16,7 \\
Superiores & 100 & $\mathbf{1 0 0}$ & $\mathbf{1 0 0}$ & $\mathbf{1 0 0}$ \\
Total &
\end{tabular}

Fuente: Encuesta nacional de inmigrantes (2007). Resultados para Andalucía. Instituto Nacional de Estadística (INE) y elaboración propia.

bién ha experimentado una evolución considerable, ya que su tasa se ha incrementado en 3,6 puntos en los últimos años, hasta situarse en el 11,3\% del total de activos en el año 2010. La mayoría de los extranjeros activos provienen de fuera de la Unión Europea, lo cual marca su carácter económico (tabla 3).

En la misma línea que la actividad, la ocupación ha experimentado, en España y en Andalucía, un incremento muy significativo en la última década. Un crecimiento que se ve truncado a partir del año 2007, puesto que la crisis económica ha destruido millones de empleos, con el consiguiente reflejo en los niveles de ocupación generales del año 2010. Pero hay un dato llamativo cuando observamos el empleo de la población extranjera: ésta ha aumentado con respecto al año 2005. Entre los años 2005 y 2010, el número de ocupados andaluces ha disminuido, mientras la ocupación de extranjeros, sobre todo los que provienen de países de la Unión Europea, ha continuado su tendencia al alza (tabla 4). Este hecho lo podemos explicar si tenemos presente la adhesión a la Unión Europea de países como Polonia, en el año 2004, y Rumanía, en el año $2007^{3}$. Estos estados miembros han exportado un relevante número de trabajadores a Andalucía en busca de

3. Documentos relativos a la adhesión de Rumanía a la Unión Europea (Diario Oficial $\mathrm{n}^{\circ} \mathrm{L}$ 157, de 21 de junio de 2005) y los respectivos a la adhesión de Polonia (Diario Oficial $n^{\circ}$ L 236, de 23 de septiembre de 2003). 
Tabla 3. Activos por nacionalidad y sexo en Andalucía. En miles y porcentajes

\begin{tabular}{|c|c|c|c|c|}
\hline \multirow[b]{2}{*}{ Andalucía/años } & \multicolumn{2}{|c|}{2005} & \multicolumn{2}{|c|}{$2010^{1}$} \\
\hline & $\begin{array}{c}\text { En } \\
\text { miles }\end{array}$ & En \% & $\begin{array}{c}\text { En } \\
\text { miles }\end{array}$ & En \% \\
\hline Varones & $2.142,2$ & 61 & 2.245 & 56,4 \\
\hline Mujeres & $1.368,3$ & 39 & $1.731,5$ & 43,6 \\
\hline Total & $3.510,5$ & 100 & $3.976,5$ & 100 \\
\hline Nacionalidad & & & & \\
\hline Nacionalidad española ${ }^{2}$ & $3.240,5$ & 92,3 & $3.530,3$ & 88,7 \\
\hline Nacionalidad extranjera & 270,0 & 7,7 & 446,2 & 11,3 \\
\hline Total & $3.510,5$ & 100 & $3.976,5$ & 100 \\
\hline Extranjeros de la Unión Europea & 48,3 & 17,8 & 149,4 & 33,4 \\
\hline Extranjeros de fuera de la Unión Europea & 221,7 & 82,2 & 296,8 & 66,6 \\
\hline Total & 270,0 & 100 & 446,2 & 100 \\
\hline
\end{tabular}

1. En las cifras del año 2010, se incluyen los 27 países de la Unión Europea (UE-27) excepto España.

2. Las personas con doble nacionalidad (española y otra) se incluyen con las de nacionalidad española.

Fuente: Encuesta de población activa. Instituto Nacional de Estadística y elaboración propia.

Cuartos trimestres.

nuevas y mejores oportunidades económicas. En este contexto, conviven dos situaciones contradictorias: por una parte, elevadas tasas de desempleo y, por otra, la demanda de mano de obra extranjera para cubrir los puestos de trabajo que los autóctonos rechazan, sobre todo por ser empleos muy precarios $^{4}$. Lo cierto es que los nuevos inmigrantes muestran niveles de exigencia mucho menores que los andaluces a la hora de buscar y aceptar un empleo. En muchas ocasiones, los empleadores prefieren contratar mano de obra inmigrante por el menor coste que conlleva, frente a la mano de obra autóctona, más exigente en cuanto a salarios y a condiciones laborales.

Como se puede apreciar en la tabla 5, siguiendo la lógica de la evolución de la actividad y del empleo, la proporción de desempleados ha experimentado, en los últimos cinco años, un significativo aumento que se atribuye al ciclo de recesión económica. En el año 2010, el número de desempleados en Andalucía es de 1.127.400, cifra que dobla la tasa media de paro española. En concreto, desde el año 2005 hasta el 2010, se ha multiplicado por cinco el número de desempleados extranjeros, los cuales llegan a representar el 14,4\% del total en Andalucía en el año 2010. Cabe destacar que la mayoría de extranjeros en situación de desempleo provienen de fuera de la Unión Europea, en consonancia con sus menores niveles educativos y con

4. En este sentido, se han definido relaciones funcionales entre ambos actores, ya que los inmigrantes buscan un trabajo y, al mismo tiempo, los autóctonos ven cubiertas sus necesidades de mano de obra en puestos de trabajo que ellos mismos no quieren ocupar (Solé y Cachón, 2006). 
Tabla 4. Ocupados por nacionalidad y sexo en Andalucía. En miles y porcentajes

\begin{tabular}{|c|c|c|c|c|}
\hline \multirow[b]{2}{*}{ Andalucía/años } & \multicolumn{2}{|c|}{2005} & \multicolumn{2}{|c|}{$2010^{1}$} \\
\hline & $\begin{array}{c}\text { En } \\
\text { miles }\end{array}$ & En \% & $\begin{array}{c}\text { En } \\
\text { miles }\end{array}$ & En \% \\
\hline \multicolumn{5}{|l|}{ Sexo } \\
\hline Varones & $1.923,7$ & 63,5 & 1.643 & 57,7 \\
\hline Mujeres & $1.101,4$ & 36,5 & $1.206,1$ & 42,3 \\
\hline Total & $3.025,1$ & 100 & $2.849,1$ & 100 \\
\hline \multicolumn{5}{|l|}{ Nacionalidad } \\
\hline Nacionalidad española ${ }^{2}$ & $2.791,2$ & 92,2 & $2.564,3$ & 90,1 \\
\hline Nacionalidad extranjera & 233,9 & 7,8 & 284,8 & 9,9 \\
\hline Total & $3.025,1$ & 100 & $2.849,1$ & 100 \\
\hline Extranjeros de la Unión Europea & 41,5 & 17,7 & 91,2 & 32,1 \\
\hline Extranjeros de fuera de la Unión Europea & 192,4 & 82,3 & 193,6 & 67,9 \\
\hline Total & 233,9 & 100 & 284,8 & 100 \\
\hline
\end{tabular}

1. En las cifras del año 2010 se incluyen los 27 países de la Unión Europea (UE-27) excepto España.

2. Las personas con doble nacionalidad (española y otra) se incluyen con las de nacionalidad española.

Fuente: Encuesta de población activa. Instituto Nacional de Estadística. Elaboración propia. Cuartos trimestres.

sus ocupaciones ubicadas en sectores productivos más sensibles a la crisis económica.

Los datos extraídos del observatorio ARGOS (2011) muestran un descenso interanual de la contratación de extranjeros en Andalucía del 9,4\%. Este hecho refleja las consecuencias del ciclo de recesión económica en el mercado de trabajo, donde el desempleo no ha parado de crecer desde el año 2007. En consonancia con esta realidad, los extranjeros demandantes de empleo han experimentado un incremento interanual del $8,7 \%$. Los principales sectores productivos donde han trabajado anteriormente corresponden a: ganadería, agricultura, silvicultura y pesca $(17,1 \%)$; construcción $(16,3 \%)$, y hostelería $(13,4 \%)$. La movilidad ocupacional no está dentro de sus expectativas más inmediatas, ya que las principales ocupaciones que demandan se corresponden con las que habían tenido antes de quedar desempleados. Cabe destacar que el 21,5\% de los demandantes de empleo no había trabajado anteriormente. El perfil del extranjero demandante de empleo en Andalucía se corresponde con ser varón $(54,5 \%)$, con una edad comprendida entre los 25 y 49 años (77\%) y con nivel de estudios primarios o inferiores (60\%). Por nacionalidades, la mayoría de los demandantes de empleo en Andalucía es de Marruecos (28,8\%), Rumanía (16,3\%) y países latinoamericanos (17,7\%), como Colombia, Ecuador, Argentina y Bolivia.

A continuación, se analiza la trayectoria de inserción laboral que experimentan los inmigrantes en Andalucía. Para ello, utilizamos los datos de la 
Tabla 5. Desempleados por nacionalidad y sexo en Andalucía. En miles y porcentajes

\begin{tabular}{|c|c|c|c|c|}
\hline \multirow[b]{2}{*}{ Andalucía/años } & \multicolumn{2}{|c|}{2005} & \multicolumn{2}{|c|}{$2010^{1}$} \\
\hline & $\begin{array}{c}\text { En } \\
\text { miles }\end{array}$ & En \% & $\begin{array}{c}\text { En } \\
\text { miles }\end{array}$ & En \% \\
\hline \multicolumn{5}{|l|}{ Sexo } \\
\hline Varones & 218,5 & 45 & 602 & 53,4 \\
\hline Mujeres & 266,9 & 55 & 525,4 & 46,6 \\
\hline Total & 485,4 & 100 & $1.127,4$ & 100 \\
\hline \multicolumn{5}{|l|}{ Nacionalidad } \\
\hline Nacionalidad española ${ }^{2}$ & 449,3 & 92,5 & 966 & 85,6 \\
\hline Nacionalidad extranjera & 36,1 & 7,5 & 161,4 & 14,4 \\
\hline Total & 485,4 & 100 & $1.127,4$ & 100 \\
\hline Extranjeros de la Unión Europea & 6,8 & 18,8 & 58,2 & 36 \\
\hline Extranjeros de fuera de la Unión Europea & 29,3 & 81,2 & 103,2 & 64 \\
\hline Total & 36,1 & 100 & 161,4 & 100 \\
\hline
\end{tabular}

1. En las cifras del año 2010 se incluyen los 27 países de la Unión Europea (UE-27) excepto España.

2. Las personas con doble nacionalidad (española y otra) se incluyen con las de nacionalidad española.

Fuente: Encuesta de población activa. Instituto Nacional de Estadística. Elaboración propia. Cuartos trimestres.

$\mathrm{ENI}^{5}$ y de la EPA, ambas fuentes del INE, referidos a dicha comunidad autónoma. Esta información se completa con las cifras del observatorio de empleo ARGOS $^{6}$, perteneciente a la Administración andaluza.

\section{Itinerarios laborales: el proceso de inserción socioprofesional}

El proceso de inserción laboral comienza con la incorporación al primer empleo y termina con la inserción laboral plena, que supone la consolidación de una situación profesional estable y adecuada a las características del individuo. Entre estas dos situaciones, inicial y final, suceden todo un conjunto de experiencias caracterizadas por su variedad y complejidad. El individuo suele desarrollar una diversidad de itinerarios o trayectorias que definen un modelo de vida y de integración en la sociedad.

En muchas ocasiones, los itinerarios laborales que describen los inmigrantes están determinados por la situación en sus países de origen y las redes sociales pre-

5. En la Encuesta nacional de inmigrantes (ENI), se consideran inmigrantes a todas aquellas personas que, no siendo su país de origen España, tienen establecida su residencia habitual en territorio nacional. Por otra parte, la situación de empleado hace referencia a cualquier actividad remunerada, ya sea estable o temporal, con contrato o sin contrato.

6. El observatorio ARGOS obtiene la estadística de contratos de las bases de datos de los servicios públicos de empleo. Por contratación, se considera tanto los contratos iniciales, como las conversiones de contratos en indefinidos y las adscripciones en colaboración social. 
Tabla 6. Situación antes de venir a Andalucía. En porcentajes

\begin{tabular}{lc}
\hline Motivos de traslado & \\
\hline Jubilación & 3,8 \\
Cambio de destino laboral & 1,8 \\
Falta de empleo & 1,5 \\
Buscar un empleo mejor & 16,2 \\
Motivos políticos & 1,5 \\
Motivos religiosos & 0,1 \\
Razones educativas & 2,8 \\
Calidad de vida & 21,5 \\
Razones familiares & 15,8 \\
Coste de la vida & 8,6 \\
Clima & 10,3 \\
Estancia temporal & 0,1 \\
Otras razones & 6 \\
Total & 100 \\
Endeudamiento para venir & \\
No pagaron nada & 9 \\
Pagaron pero no se endeudaron & 56 \\
Pagaron y quedaron endeudados & 17 \\
No saben & 18 \\
Total & 100 \\
Existencia de contactos en Andalucía & \\
Tenía contactos & 69,2 \\
No tenía contactos & 30,8 \\
Total & 100 \\
Tenía propuesta de trabajo & \\
Sí & 15,4 \\
No & 84,6 \\
Total & 100 \\
Tipo de propuesta de trabajo para venir a España & \\
Venía con precontrato de trabajo & 51,5 \\
Venía con compromiso verbal & 48,5 \\
Total & 100 \\
\hline
\end{tabular}

Fuente: Encuesta nacional de inmigrantes y elaboración propia. Resultados para Andalucía (2007).

viamente establecidas antes de su partida. Como podemos apreciar en la tabla 6 , los principales motivos por los que se trasladan obedecen a la "calidad de vida" y a motivos laborales, ya sea por la falta de empleo o para buscar otro mejor. Es preciso destacar que la mayoría (56\%) pagó para poder venir y un $17 \%$ no sólo pagó, sino que también quedó endeudada, al no contar con suficiente dinero para el viaje.

La importancia de las redes sociales se deja notar en este proceso, ya que el 69,2\% de los inmigrantes afirma poseer contactos en Andalucía antes de emigrar. La importancia de los conocidos, amigos y familiares, a la hora de 
encontrar un medio de vida se constata en este caso, ya que la práctica totalidad $(84,6 \%)$ no tenía propuesta de trabajo cuando emigró. A esta falta de previsión, hay que añadir que los que tenían una propuesta laboral, en una proporción considerable $(48,5 \%)$, era un compromiso verbal.

Las redes sociales siguen siendo la principal vía de búsqueda de empleo para el resto de activos en Andalucía y España. En concreto, el 76,1\% de los desempleados en España lo buscan a través de sus propias redes sociales (EPA, 2010). Es una característica que define a los procesos de búsqueda de empleo en países mediterráneos de la Unión Europea, como son los casos de Italia, Grecia y Portugal.

La teoría del capital relacional establece que los canales informales de acceso al empleo (amigos, parientes y conocidos) son muy eficaces a la hora de encontrar un trabajo, ya que los costes de búsqueda y acceso al mundo laboral se ven ampliamente reducidos con las redes sociales. En esta línea, Doeringer y Piore (1983) consideran que la aceptación del nuevo empleado, por parte de sus compañeros en la empresa, es fundamental para poder adquirir determinadas cualificaciones necesarias para desarrollar el trabajo. La aceptabilidad social es clave, y esta aceptación es sensible a factores como la raza, el sexo y las creencias sociales compartidas.

En el momento de emigrar, la mayoría (60\%) estaba trabajando o buscando trabajo. Por sexos, se aprecia una mayor presencia del varón en el mercado laboral, frente a la mujer que muestra más protagonismo como estudiante o en sus labores. Las diferencias más significativas las encontramos al analizar la situación de la actividad por región de nacimiento. En concreto, el $62 \%$ de los que buscaban trabajo habían nacido en América Latina y África, frente a una minoría $(9,4 \%)$ que había nacido en países desarrollados. Una situación inversa encontramos en los que afirman estar jubilados, ya que la práctica totalidad $(91,7 \%)$ corresponde a países desarrollados. Estos indicadores muestran la importancia de la inmigración de jubilados provenientes de países ricos en busca del clima y la calidad de vida que ofrece Andalucía y, por otro lado, la inmigración económica que llega de los países más pobres en busca de nuevas oportunidades laborales (Tabla 7).

Como podemos apreciar en la tabla 8 , el inicio de los itinerarios laborales ha sido muy rápido para la mayoría, ya que el $62,5 \%$ tenía un trabajo a los 30 días de haber llegado a España. En general, la práctica totalidad (94,7\%) ha tardado menos de un año en encontrar empleo y el resto (5,3\%), más de un año. Han sido muy pocos los que venían con un precontrato de trabajo $(16,6 \%)$, por lo tanto, la tónica general ha sido emprender acciones de búsqueda de empleo mediante las ayudas de los amigos y los parientes $(55 \%)$ y las solicitudes directas al empresario $(18,6 \%)$. No obstante, en la búsqueda de empleo, se suelen utilizar diferentes estrategias conjuntas. La idea de poner en marcha un negocio también resulta relevante como salida profesional, ya que el 4,7\% lo ha llevado a cabo.

En lo que respecta a la categoría laboral del primer empleo que encontraron en España (tabla 9), podemos constatar que las más elevadas, como 
Tabla 7. Situación de la actividad en el momento de emigrar por sexo y región de nacimiento. En cifras absolutas y porcentajes

\begin{tabular}{lrrrrr}
\hline & Trabajando & $\begin{array}{l}\text { Buscando } \\
\text { Trabajo }\end{array}$ & Estudiando & Jubilado & \multicolumn{1}{l}{$\begin{array}{l}\text { Sus } \\
\text { labores }\end{array}$} \\
\hline Por sexo (cifras absolutas) & & & & & \\
Varones & 139.815 & 42.868 & 31.568 & 22.780 & 11.837 \\
Mujeres & 106.349 & 30.103 & 42.320 & 11.711 & 92.860 \\
Total & 246.164 & 72.971 & 73.888 & 34.490 & $\mathbf{1 0 4 . 6 9 7}$ \\
Por región de nacimiento (en \%) & & & & \\
Países desarrollados & 29,8 & 9,4 & 22,4 & 91,7 & 24,9 \\
América Latina & 29,5 & 37,5 & 23,7 & 2,8 & 33,5 \\
África & 18,6 & 24,4 & 39,2 & - & 18 \\
Otros países de Europa, & 22,1 & 28,7 & 14,7 & 5,5 & 23,6 \\
Asia y Oceanía & 100 & 100 & 100 & 100 & 100 \\
Total & 100 & & & 100 & \\
\hline
\end{tabular}

Fuente: Encuesta nacional de inmigrantes y elaboración propia. Resultados para Andalucía (2007).

Tabla 8. El inicio de los itinerarios laborales en Andalucía. En porcentajes

\begin{tabular}{lc}
\hline Tiempo en encontrar el primer empleo & \\
\hline Precontrato & 17,6 \\
Hasta 15 días & 31,3 \\
De 15 a 30 días & 13,6 \\
De 1 a 3 meses & 16 \\
De 3 a 12 meses & 16,2 \\
Más de un año & 5,3 \\
Total & 100 \\
\hline Formas de búsqueda del primer empleo en Andalucía & \\
Contacto con oficina de empleo pública & 1,8 \\
Contacto con oficina de empleo privada & 1,4 \\
Solicitándolo al empresario & 18,6 \\
A través de amigos y parientes & 55 \\
A través de un sindicato & - \\
Por medio de anuncios y ofertas & 5,6 \\
Creando un negocio propio & 4,7 \\
Realizando exámenes y entrevistas & 2,4 \\
ONG & 0,7 \\
Otros & 8,2 \\
No sabe & 1,6 \\
Total & 100 \\
\hline
\end{tabular}

Fuente: Encuesta nacional de inmigrantes y elaboración propia. Resultados para Andalucía (2007). 


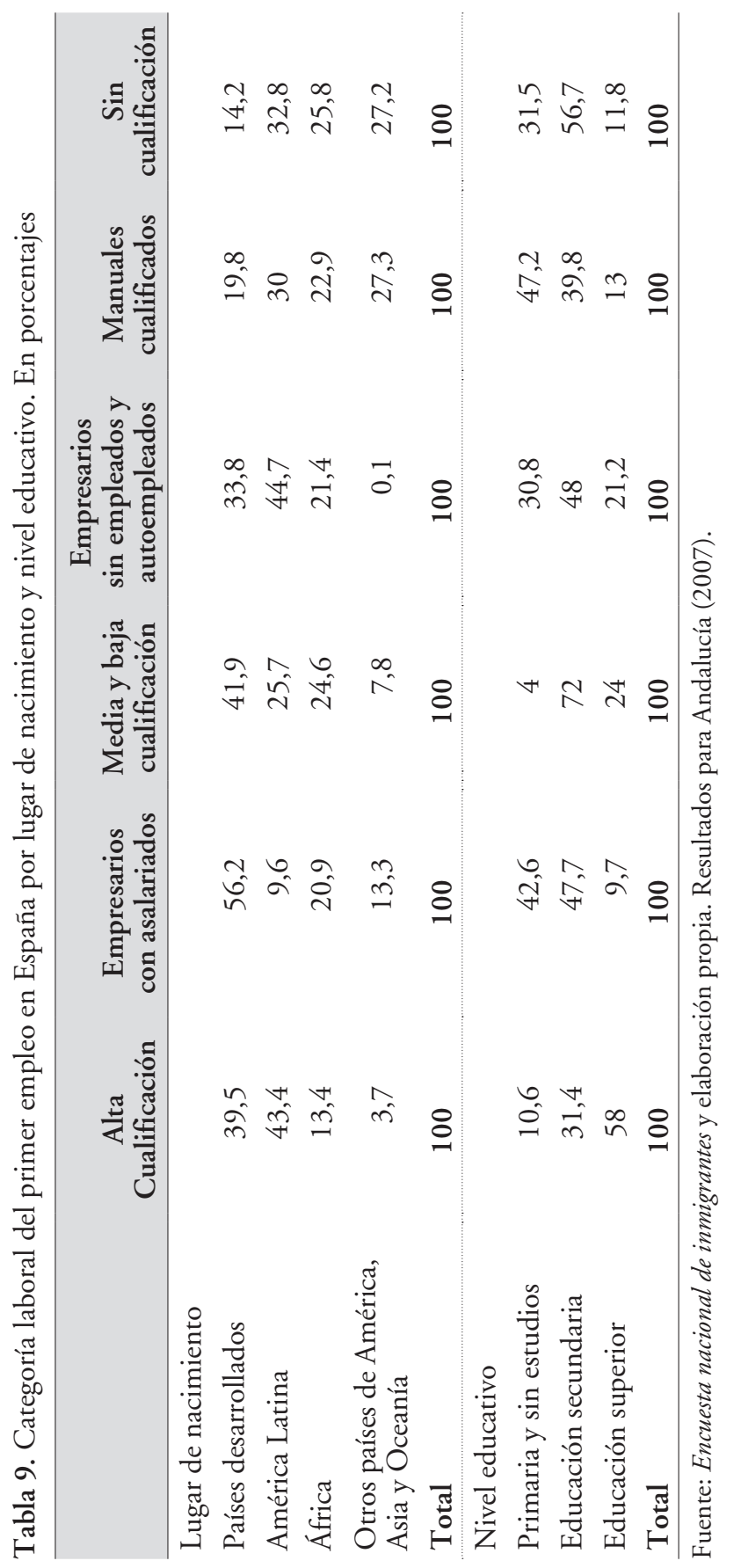


Gráfico 1. Situación laboral en Andalucía

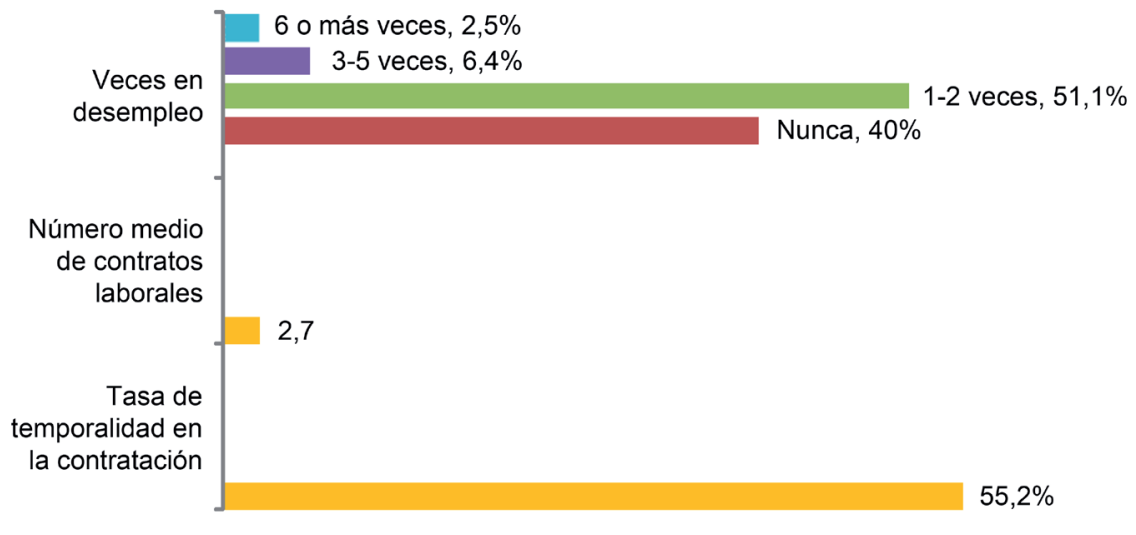

Fuente: Encuesta Nacional de Inmigrantes (INE) y elaboración propia (2007).

profesionales y técnicos de alta cualificación, las ostentan de forma notoria los inmigrantes procedentes de países desarrollados y los que poseen un nivel educativo medio y superior. Por el contrario, la inmensa mayoría de los empleados manuales cualificados y los no cualificados proceden de América Latina, África y de otros países de América, Asia y Oceanía. Es preciso resaltar que en los niveles educativos inferiores encontramos a los inmigrantes más emprendedores como empresarios, ya sea con o sin asalariados. Esta significativa correlación se puede explicar atendiendo a las escasas posibilidades de encontrar un empleo de calidad cuando se posee poca formación. Por ello, para muchos, la única salida profesional es la creación de su propio negocio.

Una vez iniciado su itinerario laboral, lo más característico es experimentar varias entradas y salidas del mercado de trabajo. En concreto, la mayoría (60\%) ha estado alguna vez en desempleo. El número medio de contratos laborales es de 2,7 por inmigrante, y la tasa de temporalidad en la contratación es del $55,2 \%$ (gráfico 1). La flexibilización del mercado de trabajo afecta a todos los grupos de población, pero de forma más acusada a los inmigrantes. Cabe destacar que España y Andalucía ostentan unos elevados niveles de temporalidad en la contratación, ya que doblan la media de la Unión Europea. En concreto, en Andalucía la temporalidad se sitúa en el 33,8\% y a nivel nacional en el 24,8\% del total de los contratos de trabajo (EPA, 2010).

En lo que respecta a la categoría laboral actual (tabla 10), se sigue apreciando la tendencia que marca el protagonismo de los inmigrantes procedentes de los países desarrollados a la hora de ocupar los trabajos de mayor cualificación, en consonancia con los niveles educativos superiores. Por el contrario, los procedentes de América Latina y África ocupan la mayoría de empleos de baja cualificación. El autoempleo sigue ocupando un lugar relevante como salida laboral en los inmigrantes con bajos niveles educativos. 


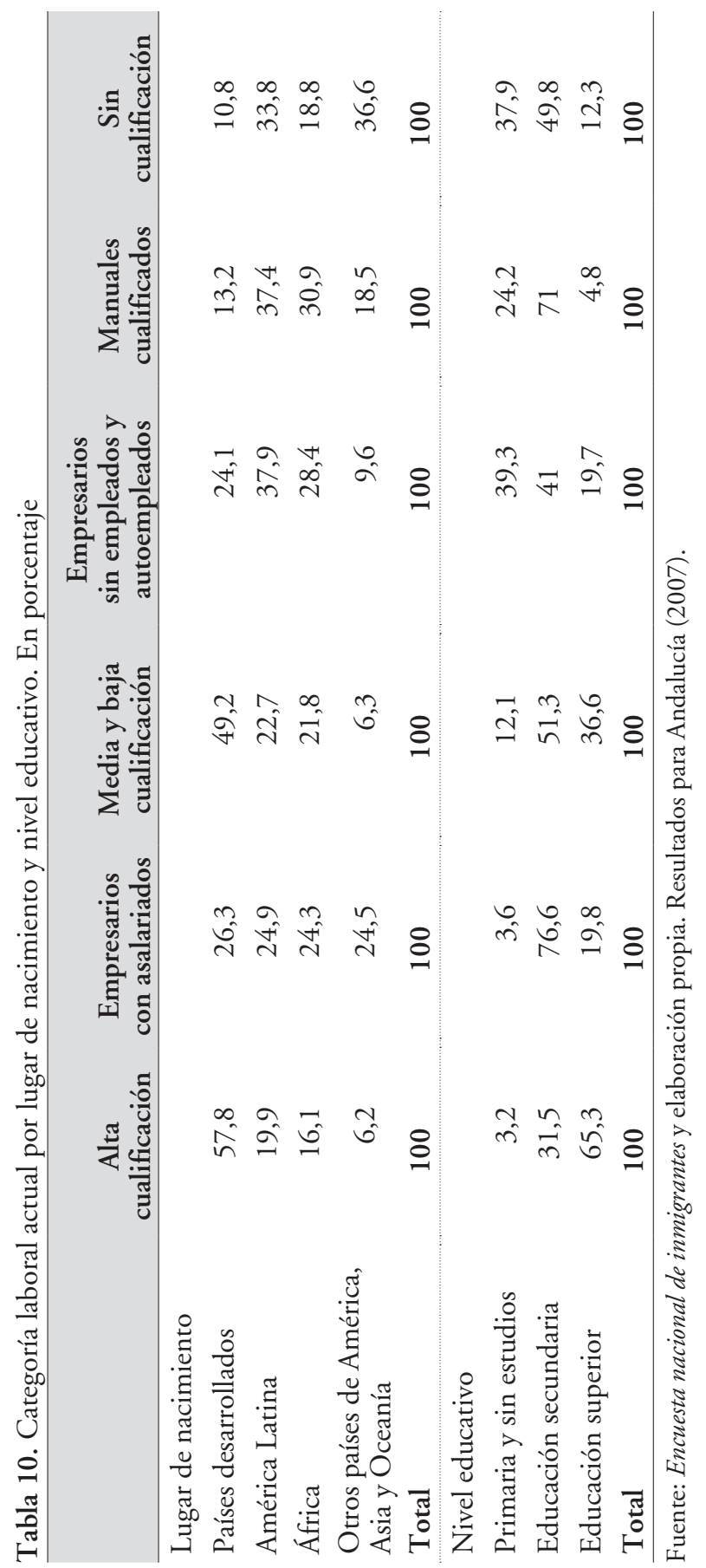


Los datos del observatorio ARGOS (2011) muestran que la demanda de mano de obra inmigrante en sectores como agricultura, ganadería, silvicultura y pesca viene siendo habitual. La mayoría (67.2\%) trabaja en lo que se denominan ocupaciones elementales, caracterizadas por no requerir cualificación. De los extranjeros contratados, poco más de la mitad $(57,1 \%)$ poseen estudios primarios o inferiores, y una significativa mayoría $(73,4 \%)$ tiene una edad comprendida entre los 25 y los 44 años. El tipo de contrato predominante $(96,7 \%)$ es el temporal. Las principales nacionalidades de las personas contratadas en Andalucía corresponden a los países de Marruecos y Rumanía. En menor medida, cabe destacar los nacionales de otros países como Ecuador, Bolivia, Portugal, Italia, Polonia, Malí, Argelia, Argentina, Reino Unido y Colombia.

En general, destaca la escasa movilidad profesional ascendente de los inmigrantes. Este hecho, junto con su situación laboral precaria, se puede explicar, en cierta medida, por el papel que las redes sociales desempeñan a la hora de ubicarlos espacial y profesionalmente. Los amigos, los conocidos y los familiares les proporcionan los apoyos necesarios para venir a Andalucía y para instalarse en los guetos y las profesiones elementales que ya ocupan. De este modo, la reproducción de las situaciones materiales y sociales queda, en buena medida, asegurada.

Otros factores relevantes en la integración de los inmigrantes hacen referencia al hogar y a la familia (tabla 11). La mayoría de los inmigrantes viven con su pareja, ya sea con hijos $(43,9 \%)$ o sin hijos $(22,3 \%)$. Un dato a destacar es la elevada proporción de los que afirman vivir en una vivienda en propiedad $(38,2 \%)$, que podemos explicar aludiendo a los inmigrantes procedentes de países desarrollados que se instalan en España largos periodos de tiempo motivados por el clima y la calidad de vida. No obstante, para la mayoría, el régimen de uso de la vivienda es en alquiler o cedida $(60,2 \%)$. Se trata de la pauta más habitual en el alojamiento de los inmigrantes económicos.

Los tópicos asociados a los inmigrantes, procedentes de países más pobres, aluden a la precariedad de la vivienda y su ubicación en las zonas más deprimidas y problemáticas. Cuando se les pregunta por la existencia de problemas en su hábitat, la mayoría señala que vive en un entorno con problemas $(56,9 \%)$. Entre los principales problemas, destacan los ruidos exteriores $(17,6 \%)$, la falta de limpieza en las calles $(17,2 \%)$, los problemas con el servicio de correos $(12 \%)$, la humedad en la vivienda $(11,4 \%)$ y la delincuencia en la zona $(10,2 \%)$. En menor medida, destacan otros aspectos, como los malos olores, las deficiencias constructivas, las malas comunicaciones y la falta de espacio en la vivienda.

Es importante destacar sus planes más inmediatos, así como las relaciones con el país de origen y la sociedad española (tabla 12). En lo que respecta a sus expectativas más inmediatas, una significativa mayoría $(85,7 \%)$ piensa permanecer en España durante los próximos cinco años, y tan sólo una minoría opina que regresará a su país de nacimiento $(4,6 \%)$ o se trasladará a otro país $(1,3 \%)$. 
Tabla 11. Hogares y familias de los inmigrantes. En porcentajes

\begin{tabular}{lc}
\hline Tipo de hogar & \\
\hline Unipersonal & 7,8 \\
Hogares sin núcleo & 10,6 \\
Monoparentales & 9,4 \\
Pareja con hijos & 43,9 \\
Pareja sin hijos & 22,3 \\
Varias parejas con y sin hijos & 6 \\
Total & 100 \\
Régimen de uso de la vivienda & \\
Propiedad & 38,2 \\
Alquiler & 39,1 \\
Cedida & 21,2 \\
Otras situaciones & 1,5 \\
Total & 100 \\
Problemas en el hábitat & \\
Buen entorno & 43,1 \\
Entorno con problemas & 56,9 \\
Total & 100 \\
Problemas en su vivienda y en el entorno & \\
Ruidos exteriores & 17,6 \\
Malos olores & 8,8 \\
Humedad & 11,4 \\
Deficiencias constructivas & 7,8 \\
Poca limpieza en las calles & 17,2 \\
Delincuencia en la zona & 10,2 \\
Mal comunicada & 6,3 \\
Problemas con el servicio de correos & 12 \\
Vivienda demasiado pequeña & 8,7 \\
Total & 100 \\
\hline Fuente: Encuesta nacional de inmigrantes y elaboración propia. Resultados para Andalucia $(2007)$ \\
(n)
\end{tabular}

En cuanto a la participación social, cabe mencionar que tan sólo una minoría $(13,1 \%)$ participa en alguna organización orientada a los inmigrantes. Las más representativas corresponden a grupos de carácter social (29,1\%), educativo y cultural $(26 \%)$ y de ayuda al inmigrante $(20,8 \%)$. Las relaciones con el país de origen constituyen una pauta general, ya que el $85,6 \%$ mantiene contactos con familiares o con amigos que residen allí. Además, el 31,7\% afirma enviar remesas económicas al país de nacimiento, una proporción muy elevada si tenemos presente que un importante grupo $(43,9 \%)$ vive en España en pareja y con hijos. 
Tabla 12. Relaciones con el país de origen y con la sociedad andaluza. En porcentajes

\begin{tabular}{|c|c|}
\hline \multicolumn{2}{|l|}{ Planes para los cinco próximos años } \\
\hline Regresar a mi país de nacimiento & 4,6 \\
\hline Permanecer en España & 85,7 \\
\hline Trasladarme a otro país & 1,3 \\
\hline No sabe & 8,4 \\
\hline Total & 100 \\
\hline \multicolumn{2}{|c|}{ Participación en organizaciones orientadas a inmigrantes } \\
\hline Participan & 13,1 \\
\hline No participan & 86,9 \\
\hline Total & 100 \\
\hline \multicolumn{2}{|l|}{ Tipo de organizaciones en las que participan } \\
\hline Grupos de carácter social & 29,1 \\
\hline Entidades y grupos religiosos & 13,7 \\
\hline Grupos educativos y culturales & 26 \\
\hline Clubes deportivos & 10,4 \\
\hline Organizaciones de ayuda al inmigrante & 20,8 \\
\hline Total & 100 \\
\hline \multicolumn{2}{|c|}{ Contactos con familiares y/o amigos en el país de origen } \\
\hline Sí & 85,6 \\
\hline No & 11,5 \\
\hline No tiene & 2,9 \\
\hline Total & 100 \\
\hline \multicolumn{2}{|c|}{ Envío de remesas de dinero al país de nacimiento } \\
\hline Envía & 31,7 \\
\hline No envía & 68,2 \\
\hline Total & 100 \\
\hline
\end{tabular}

Fuente: Encuesta nacional de inmigrantes y elaboración propia. Resultados para Andalucía (2007).

\subsection{Trayectoria socioprofesional más habitual de los inmigrantes en Andalucía}

Como podemos apreciar en la figura 1, el perfil del inmigrante en Andalucía se corresponde con ser varón, en edad activa y con un nivel educativo más bien bajo. Una importante mayoría tenía contactos en Andalucía antes de venir $y$, en una proporción considerable (17\%), quedaron endeudados para poder sufragar los gastos del viaje.

La práctica totalidad $(84,6 \%)$ no tenía una propuesta de trabajo en Andalucía y la minoría $(15,4 \%)$ que sí contaba con ello, casi la mitad eran de tipo verbal. La importancia de las redes sociales se hace patente a lo largo de su incorporación en la nueva sociedad de acogida. Prueba de ello es el poco tiempo que tardaron en encontrar su primer trabajo. Una significativa mayoría $(78,5 \%)$ tardaron menos de tres meses en entrar en el mercado laboral. Aunque suelen utilizar varios mecanismos simultáneos de búsqueda de empleo, el más eficaz y utilizado son los amigos, los conocidos 
Figura 1. Trayectoria socioprofesional de los inmigrantes en Andalucía

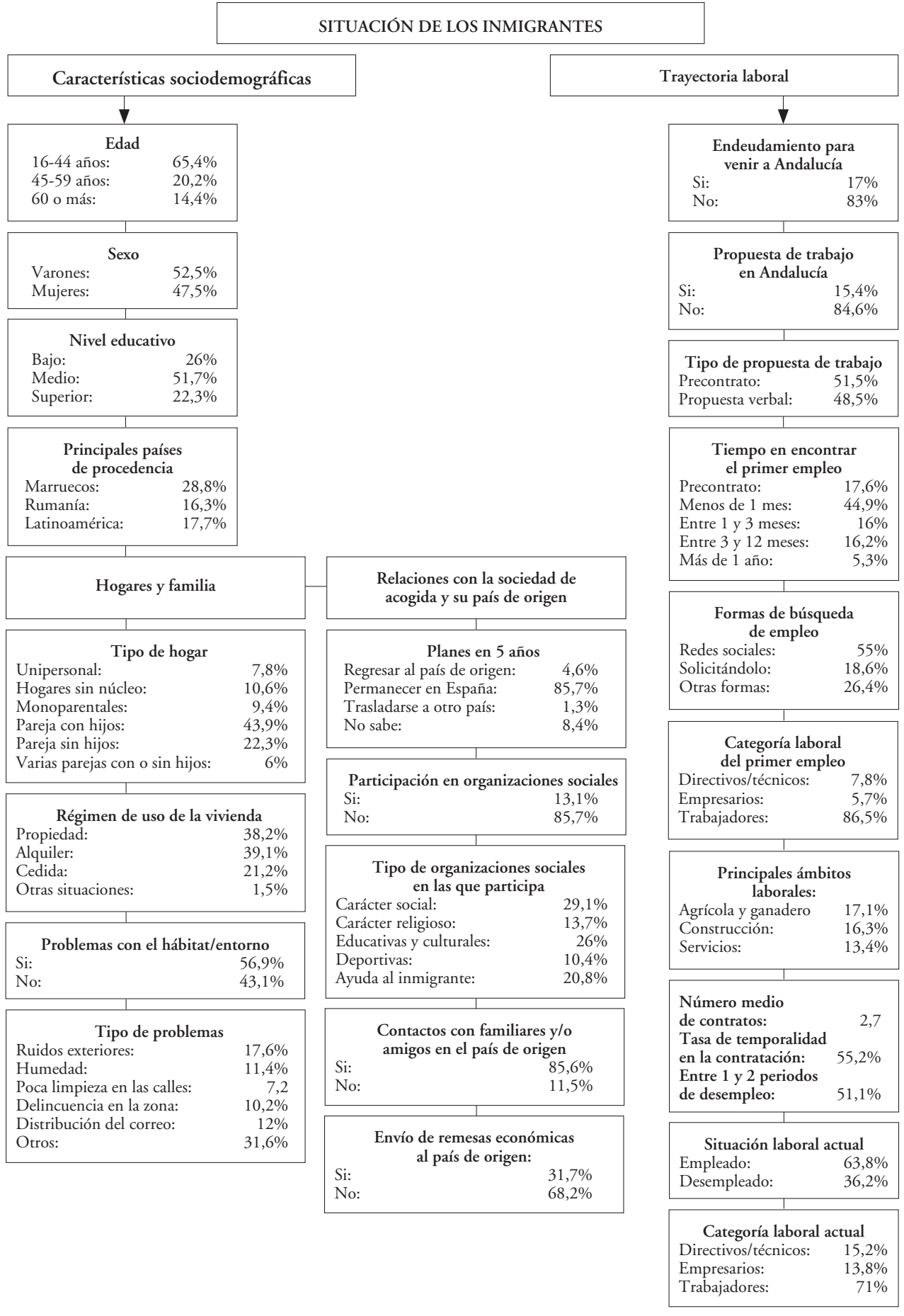


y los familiares. Las redes sociales proporcionan información privilegiada y facilita a los empleadores la mano de obra adecuada para sus necesidades. Para muchos autores, las redes sociales, como medios de integración sociolaboral, han traído consigo la reproducción de las situaciones que caracterizan a los inmigrantes económicos, es decir: precariedad laboral, pobreza y guetos. La categoría laboral del primer empleo es baja y, por lo general, desarrollan trabajos en el sector primario, en la construcción y en la hostelería.

La categoría actual ha supuesto una mejora sensible en su situación, pero poco significativa. En general, siguen ocupando las situaciones más precarias del mercado laboral. Sus trayectorias de trabajo están marcadas por la temporalidad y la rotación externa. La mayoría ha experimentado varios periodos de desempleo y los niveles de temporalidad son mucho más elevados que los correspondientes al contexto andaluz en general.

En lo que respecta a los aspectos relativos al ámbito privado, como es el hogar y la familia de los inmigrantes, hay que destacar que lo más habitual es vivir en pareja, ya sea con o sin hijos, la vivienda suele ser en alquiler o cedida y afirman tener problemas relativos al entorno donde viven. Los principales problemas que señalan son los ruidos exteriores, la poca limpieza, la humedad y la delincuencia. Por lo general, habitan zonas periféricas, donde la distribución del correo postal no está garantizada en todos los casos.

Aunque no viven en las mejores condiciones, el 85,7\% piensa permanecer en España y sólo el 4,6\% piensa regresar a su país de origen. La participación en organizaciones sociales es baja, ya que sólo el 13,1\% afirma que forma parte de alguna. Por orden de importancia, colaboran en las de carácter social, educativo y cultural, en las de ayuda al inmigrante, religiosas y deportivas. Su bajo nivel de participación se puede explicar en función de la tipología de empleos que realizan y por la significativa influencia que las redes sociales desempeñan en todo su proceso de incorporación a la nueva sociedad, incluso desde antes de partir hacia su destino.

La práctica totalidad $(85,6 \%)$ sigue manteniendo contacto con amigos y familiares de su país de origen y una proporción considerable $(31,7 \%)$ envía remesas de dinero, lo cual reafirma el carácter económico de dicha inmigración. En las investigaciones llevadas a cabo por Fernández (2010), se pone de manifiesto la importancia de las redes sociales familiares en el país de destino, ya que les facilitan capital social, información y búsqueda de empleo. Los procesos de reagrupación familiar dotan de estabilidad a los inmigrantes en las sociedades de acogida.

Siguiendo las aportaciones de diferentes investigaciones realizadas en el contexto español sobre los modelos de transición a la vida activa y al trabajo, la modalidad de trayectoria que en mayor medida define a los inmigrantes se corresponde con la trayectoria en precariedad . Esta modalidad corresponde a

7. Para ampliar información sobre estos aspectos, se pueden consultar las aportaciones del 
una inserción profesional marcada por la ausencia de estabilidad y continuidad (paros intermitentes, rotación laboral y subocupación). El modelo de transición precaria puede desencadenar en una inserción definitiva, en el supuesto de acceder a un trabajo estable, pero la excesiva rotación laboral externa y los continuos cambios de ocupación dificultan la especialización profesional en el puesto de trabajo y, como consecuencia de ello, la estabilidad laboral.

\section{Conclusiones}

Las políticas migratorias han contemplado la integración de los inmigrantes en la sociedad como un objetivo transversal en las diferentes actuaciones emprendidas. El ámbito sociolaboral ha tenido una especial relevancia en ello, ya que determina todo un conjunto de factores fundamentales para poder hablar de integración social. De hecho, el $75 \%$ de sus ingresos proceden de la actividad laboral y el trabajo aparece como su principal preocupación y necesidad (Pérez y Rinken, 2005).

El análisis de las trayectorias laborales de los inmigrantes económicos en Andalucía pone de manifiesto la segmentación del mercado de trabajo. La segregación ocupacional de la población inmigrante constituye una realidad, al ser relegada a los puestos de trabajo más precarios. Se ubica en sectores donde escasea la mano de obra autóctona, al estar caracterizados por bajos salarios, largas jornadas laborales, ausencia de contrato y, por tanto, de derechos y protección social. La temporalidad en la contratación y el cambio continuo de ocupaciones definen sus itinerarios laborales.

No obstante, y siguiendo las aportaciones de Pumares y otros (2006), se produce una etnoestratificación, ya que los inmigrantes procedentes de la Unión Europea ostentan los niveles educativos más elevados y las mejores condiciones laborales, frente a los africanos, que ocuparían la base jerárquica con empleos ubicados, en su mayoría, en la agricultura y la ganadería. Entre estas dos posiciones jerárquicas, podemos ubicar a los iberoamericanos, que ocupan lugares intermedios y heterogéneos, con una presencia importante en los empleos de oficina y en servicios domésticos, hostelería y agricultura; y a los asiáticos, con una presencia mayoritaria en el sector servicios.

En general, los inmigrantes en Andalucía suelen experimentar las denominadas trayectorias en precariedad, caracterizadas por la ausencia de estabilidad y continuidad, con paros intermitentes, rotación laboral y subocupación. Estas situaciones obligan a posponer la inserción socioprofesional plena, ya que la precariedad laboral, que les caracteriza, limita sus posibilidades de integración social óptima.

GRET (Grup de Recerca Educació i Treball), creado en 1987 y constituido por un equipo de investigadores centrados, entre otras líneas de investigación, en el estudio de las relaciones entre educación y trabajo, especialmente desde la perspectiva del análisis de la transición profesional. Este grupo de investigación está ubicado en la Facultad de Ciencias Políticas y Sociología de la Universidad Autónoma de Barcelona (http://www.uab.cat/gret). 
La apropiación de los mercados de trabajo más precarios por parte de los inmigrantes trae consigo unas consecuencias sociales, que se plasman en el bajo estatus que la sociedad autóctona les atribuye, y económicas, marcadas por procesos de segregación con concentraciones en los barrios más degradados y con deficientes condiciones de vida. Por ello, los procesos de integración en la sociedad de acogida deben de tener presentes las condiciones donde quedan relegados. El hecho de que los inmigrantes ocupen los puestos de trabajo desechados por la población autóctona contribuye a su denigración como individuos y les hace más proclives a ser reclutados en la conducta desviada o delictiva (Solé y otros, 2000).

Los procesos actuales de inmigración y su precarización corren paralelos a procesos de exclusión social y de vivencia de condiciones sociales marginales. Todo ello nos lleva a un incremento de los rechazos de la población autóctona hacia la población extranjera. De hecho, buena parte de la población inmigrante no está integrada de forma adecuada en los países de acogida, ni lo pretende hacer de forma plena (Tezanos, 2006).

Los factores institucionales tienen que ver con la génesis del rechazo, al transmitir la Administración una imagen marcada por las medidas policiales. Los inmigrantes se perciben como un colectivo que supone una carga social, una competencia laboral y demográfica y un peligro de disolución de nuestras normas y costumbres. La inmigración se asocia a una mayor inseguridad ciudadana (controles policiales continuos, ilegalidad, irregularidades) y se asocia con condiciones materiales que refuerzan los estereotipos hacia los inmigrantes (guetos, viviendas insalubres, bolsas de pobreza y economía sumergida) (Solé y otros, 2000).

Las tendencias de las migraciones apuntan a que seguirán aumentando los flujos de los países pobres a los más ricos. Los procesos migratorios deben ser atendidos como una cuestión primordial de carácter global, para ello se ha de propiciar un crecimiento económico global y dejar de lado soluciones parciales. Se ha de potenciar la cooperación y el desarrollo (Tezanos, 2006). En el mismo sentido, las investigaciones sobre integración social de los inmigrantes, llevadas a cabo en diferentes ciudades europeas por Penninx y Martiniello (2006), han puesto de manifiesto la necesidad de adoptar una perspectiva integral. No sólo es relevante el punto de vista de los autóctonos, sino también el de los propios inmigrantes, como sujetos que han de estar involucrados en el proceso de integración. Han de ser acciones a largo plazo, constantes y se ha de potenciar su descentralización a nivel local.

\section{Bibliografía}

argoS (Sistema de Prospección Permanente del Mercado de Trabajo) (2011). Evolución de la demanda de empleo en el mes de febrero. Sevilla: Consejería de Empleo. Junta de Andalucía.

- (2010). Evolución de la demanda de empleo en el mes de enero. Sevilla: Consejería de Empleo. Junta de Andalucía.

- (2008). Las personas extranjeras en el mercado laboral andaluz. Sevilla: Consejería de Empleo. Junta de Andalucía. 
Ashforth, Blake E. y SAKs, Alan M. (1995). «Work-role transitions: A longitudinal examination of the Nicholson model». Journal of Occupational and Organizational Psychology, 68,157-175.

Auberni, Salvador (comp.) (1995). La orientación profesional. Barcelona: Institut Municipal d'Educació.

Carrasco, Concepción y Riesco, Alberto (2011). «La trayectoria de inserción laboral de los jóvenes inmigrantes». Papers: Revista de Sociología, 96, 189-203.

Casal, Joaquim; Masjuan, Josep M. y Planas, Jordi (1991). La inserción social y profesional de los jóvenes. Madrid: CIDE. Ministerio de Educación y Ciencia.

Coleman, James y Husén, Torsten (1989). Inserción de los jóvenes en una sociedad en cambio. Madrid: Narcea.

Doeringer, Peter B. y Piore, Michael J. (1983). «El paro y el mercado de trabajo». En: Toharia, Luis (ed.). El mercado de trabajo: teorías explicativas. Madrid: Alianza.

ENI (Encuesta Nacional de Inmigrantes) (2007). Madrid: Instituto Nacional de Estadística.

EPA (Encuesta de Población Activa) (2010). Madrid: Instituto Nacional de Estadística. IV trimestre.

- (2005). Madrid: Instituto Nacional de Estadística. IV trimestre.

FERnÁndeZ, Mercedes (2010). Encuesta nacional de inmigrantes 2007: El mercado de trabajo y las redes sociales de los inmigrantes. Madrid: Ministerio de Trabajo e Inmigración. Colectivo IOÉ.

Figuera, Pilar (1996). La inserción del universitario en el mercado laboral. Barcelona: EUB.

Gareth, Dale y Cole, Mike (1999). The european union and migrant labour. Nueva York: Oxford.

Herrera, Encarna (1994). "Reflexiones en torno al concepto de integración en la sociología de la inmigración». Papers: Revista de Sociología, 43, 71-76.

Martínez, Manuel F.; García, Manuel y Maya, Isidro (2008). La integración social de los inmigrantes desde los recursos sociales. Sevilla: Universidad de Sevilla.

MARTíneZ, Rafael (2002). La inserción laboral de los universitarios. Granada: Universidad de Granada.

OPAM (Observatorio Permanente Andaluz de las Migraciones) (2008). Informe anual Andalucía Inmigración. Sevilla: Junta de Andalucía.

Pennix, Rinus y Martiniello, Marco (2006). "Procesos de integración y políticas (locales): Estados de la cuestión y algunas enseñanzas». Revista Española de Investigaciones Sociológicas, 116, 123-156.

PÉrez, Manuel y RINken, Sebastián (2005). La integración de los inmigrantes en la sociedad andaluza. Madrid: Consejo Superior de Investigaciones Científicas.

PMCA (Padrón Municipal Continuo de Habitantes) (2010). Madrid: Instituto Nacional de Estadística.

Poole, Michael E.; Langan-Fox, Janice y Omodei, Mary M. (1993). «Contrasting Subjective and objetive criteria as determinants of perceived career success: A longitudinal study». Journal of Occupational and Organizational Psychology, 66, 39-54.

Pumares, Pablo e Iborra, Juan F. (2008). «Población extranjera y política de inmigración en Andalucía». Política y Sociedad, 1 (45), 41-60.

Pumares, Pablo; García, Arlinda y Asensio, Ángeles (2006). La movilidad laboraly geográfica de la población extranjera en España. Madrid: Ministerio de Trabajo y Asuntos Sociales (OPIM). 
Rosell, María D. (dir.) (2008). Las personas extranjeras en el mercado de trabajo andaluz. Sevilla: Servicio Andaluz de Empleo. Junta de Andalucía.

Solé, Carlota; Sordé, Teresa; Serrandel, Olga; Alcalde, Rosalina; Flecha, Ainhoa; Georgeta, Alisa; Cavalcanti, Leonardo; Parella, Sonia; PÁvez, Iskra; SantaMARÍA, Enrique y Garzón, Luis (2011). «Cohesión social e inmigración». Revista Internacional de Sociología, 1 (69), 9-32.

Solé, Carlota (1988). Catalunya, societat receptora d'immigrants: Anàlisi comparativa de dues enquestes: 1978 i 1983. Bacelona. Institut d'Estudis Catalans.

Solé, Carlota; Alcalde, Rosa; Pont, Josep; Lurbe, Kátia y Parella, Sonia (2002). «El concepto de integración desde la sociología de las migraciones». Migraciones, $12,9-41$.

Solé, Carlota y Cachón, Lorenzo (2006). «Globalización e inmigración: los debates actuales». Revista Española de Investigaciones Sociológicas, 116, 13-52.

Solé, Carlota; Parella, Sonia; Alarcón, Amando; Bergalli, Valeria y Gilbert, Francesc (2000). «El impacto de la inmigración en la sociedad receptora». Revista Española de Investigaciones Sociológicas, 90, 131-157.

Tezanos, José F. (2006). «Nuevas tendencias migratorias y sus efectos sociales y culturales en los países de recepción: Doce tesis sobre la inmigración y la exclusión social». Revista Española de Investigaciones Sociológicas, 116, 11-34.

Tezanos, José F. y Díaz, Verónica (2008). Condiciones laborales de los trabajadores inmigrantes en España. Madrid: Sistema.

UrTeaga, Eguzki (2010). «Los modelos de integración en Europa». Nómadas: Revista Critica de Ciencias Sociales y Jurídicas, 26, 25-39. 